\title{
Functional connectivity within conservation networks: delineating corridors for African elephants
}

C. L. Roever. Conservation Ecology Research Unit, Department of Zoology and Entomology, University of Pretoria, Hatfield, South Africa 0083. E-mail: mail@carrieroever.com

R. J. van Aarde. Conservation Ecology Research Unit, Department of Zoology and Entomology, University of Pretoria, Hatfield, South Africa 0083. E-mail: rjvaarde@zoology.up.ac.za

K. Leggett. University of New South Wales Arid Zone Research Station, University of New South Wales, New South Wales, Australia. E-mail: k.leggett@unsw.edu.au

Corresponding author: C. L. Roever. Conservation Ecology Research Unit, Department of Zoology and Entomology, University of Pretoria, Hatfield, South Africa 0083. Phone: +27 12420 2753. Fax: +27 12420 4523. E-mail: mail@carrieroever.com 
Abstract

Managing multiple parks, reserves, and conservation areas collectively as conservation networks is a recent, yet growing trend. But in order for these networks to be ecologically viable, the functional connectivity of the landscape must be ensured. We assessed the connectivity between six African savanna elephant populations in southern Africa to test whether existing conservation networks were functioning and to identify other areas that could benefit from being managed as conservation networks. We used resource selection function models to create an index of habitat selection by males and female elephants. We employed this habitat use index as a resistance surface, and applied circuit theory to assess connectivity between adjacent elephant populations within six clusters of protected areas across southern Africa. Circuit theory current flow maps predicted a high likelihood of connectivity in the central portion of our study area (i.e. between the Chobe, Kafue, Luangwa, and Zambezi cluster). Main factors limiting connectivity across the study area were high human density in the east and a lack of surface water in the west. These factors effectively isolate elephants in the Etosha cluster in Namibia and Niassa clusters in Mozambique from the central region. Our models further identified two clusters where elephants might benefit from being managed as part of a conservation network, 1) northern Zambia and Malawi and 2) northern Mozambique. We conclude that using habitat selection and circuit theory models to identify conservation networks is a data-based method that can be applied to other focal species to identify and conserve functional connectivity. 


\section{Keywords:}

African elephant, circuit theory, corridor, habitat selection, Loxodonta africana, resource selection function.

\section{Introduction}

As the human world becomes more connected, wildlife and wild lands become increasingly fragmented (Crooks and Sanjayan 2006). Historically, the world's biodiversity was preserved through the establishment of parks and protected areas, but current initiatives are moving towards increasing connectivity between these wildlife islands (Hanks 2001; van Aarde and Jackson 2007). The establishment of transfrontier conservation areas (TFCA) and corridors interconnecting multiple protected areas, such as the Kavango-Zambezi TFCA in southern Africa and the Yellowstone to Yukon Corridor in the North America, are an increasing trend. The objectives of these conservation networks differ, but most generally include increasing connectivity or promoting dispersal and migration. Thus once a conservation network has been established, the first step to achieve these objectives is to identify, maintain, and where necessary increase functional connectivity on the landscape (Hanks 2001).

Large mammals are of particular interest for conservation networks because these species operate at broad spatial scales and consequently their populations are more likely to be fragmented (Crooks 2002). Large mammals are also often in direct competition with humans; predators compete with human-hunters for game (e.g. Brown and Conover 2011; Herfindal et al. 2005), ungulates and ruminants harbour diseases which infect domestic animals (e.g. Corner 2006), and herbivores damage gardens and crops (e.g. Conover and Kania 1995; Madhusudan 
2003). Consequently, many large mammal species are restricted to protected areas or areas with low human density (Morrison et al. 2007). Functional conservation network that will address the landscape needs of large mammals must promote dispersal between parks, particularly through the establishment of corridors (Hanks 2001). Corridors are defined as continuous strips of land that facilitate animal movement across the landscape (Beier and Noss 1998; Puth and Wilson 2001). They reduce the effects of habitat loss and fragmentation and may increase genetic mixing (Crooks and Sanjayan 2006).

Corridors that increase functional connectivity for large mammals may also restore essential ecological processes. Large herbivores, in particular, aid in long-distance seed dispersal (Janzen 1984), effectively reducing the isolation of some plant species in small reserves (Couvreur et al. 2004). Some large herbivores are also ecosystem engineers that can transform plant communities (see Hobbs 1996; Manier and Hobbs 2006; Pringle et al. 2007). Occasionally such transformation is undesirable, and this has become a particular management concern for African savanna elephants (Loxodonta africana). In southern and East Africa, elephants at high densities have the ability to transform woodlands to shrublands or grasslands (Dublin et al. 1990; Scholes and Mennell 2008; Western and Maitumo 2004). Their confinement and compression into anomalously small areas likely accentuates their transformative influences (Loarie et al. 2009b; van Aarde et al. 2006). Historical long-distance movements was believed to limit local overgrazing (Coughenour 2008), but today long-distance migration among terrestrial vertebrates is one of the world's most endangered biological phenomenon (Bartlam-Brooks et al. 2011; Berger 2004). 
Restoring elephant movements between protected areas and managing elephants as spatially structured metapopulations has been proposed by van Aarde and Jackson (2007) as a means to reduce local impact, reduce the need for elephant culling, and stabilize elephant numbers regionally. This study will test whether corridors currently exist between protected areas and if already established conservation networks are functionally connected for elephants. Opportunities for dispersal may exist in southern Africa because protected areas are within close proximity of each other and are embedded in a matrix of mostly untransformed habitats with few people (Cushman et al. 2010; Mittermeier et al. 2003). Furthermore, elephants are ideal candidates for designing corridors because they are an umbrella species, often co-occurring with other species of conservation concern (Epps et al. 2007). In this paper, we will assess the potential for connectivity between existing elephant populations in southern Africa using circuit theory and resource selection function (RSF) models.

Circuit theory is based on a random walk, with connectivity between habitat patches increasing with the number of alternative routes and decreasing with distance (McRae et al. 2008). Circuit theory uses the principles of an electric circuit, where a current (animal) flows through nodes and resistors (habitat patches and matrix) with voltage (probability of animal travel) and resistance (permeability of habitat types; McRae et al. 2008). The resulting product is a prediction of 'current density' or a probability of movement across each pixel of the landscape. Among the benefits of circuit theory is that it does not assume perfect knowledge of the landscape (McRae et al. 2008). To identify habitats with the greatest flow and least resistance to movements, we will use a RSF model. An RSF model compares used and available resource units to estimate the probability of occurrence (Boyce et al. 2002; Manly et al. 2002). 
We assume that habitat types that are avoided provide greater resistance to movement (Chetkiewicz et al. 2006; McRae et al. 2008). While our objective was to determine the likelihood of connectivity between known elephant populations in southern Africa, our approach could also help managers enhance or promote potential corridors for other species.

\section{Methods}

\subsection{Study Area}

Located in southern Africa, our study area extended from the western to the eastern coast and encompassed portions of Angola, Botswana, Malawi, Mozambique, Namibia, Zambia, and Zimbabwe (Figure 1). Within the study area, we identified six clusters of protected areas within which elephant populations were known or suspected to be interconnected (see Van Aarde and Ferreira 2009). Habitats varied across clusters from predominantly arid grassland in Namibia to mesic woodlands in Mozambique. Terrain was relatively flat across most of the study area, except near the Etendeka Mountains in western Namibia and the Muchinga Mountains in

Table 1. Euclidian distance between neighboring clusters of elephant data arranged from west to east.

\begin{tabular}{lc}
\hline Cluster & $\begin{array}{c}\text { Distance between } \\
\text { neighboring clusters }(\mathrm{km})\end{array}$ \\
\hline Etosha and Chobe & 300 \\
Chobe and Kafue & 180 \\
Kafue and Zambezi & 300 \\
Zambezi and Luangwa & 320 \\
Luangwa and Niassa & 430 \\
\hline
\end{tabular}


Zambia. The distance between neighbouring clusters varied from 180 to $430 \mathrm{~km}$ (Table 1). Two conservation networks occurred within the study area, the Kavango-Zambezi TFCA which included the Chobe and Kafue cluster and the Niassa-Selous corridor located north of the Niassa cluster (Figure 1). Human presence was relatively low across the region, with pockets of increased human densities near major waterways and roadways. Elephants were generally free roaming, except where fences existed, either along the borders of protected areas (Etosha National Park) or along international boundaries (between Namibia and Botswana).

\subsection{Elephant Data}

Between December 2002 and September 2010, 93 elephants were captured and collared with Africa Wildlife Tracking GPS collars (model SM 2000E). Collars were programmed to locate individuals at varying intervals, ranging from 1 to 24 hours, with most animals having multiple interval settings during the tracking period. Elephants are less mobile during the dry season and more faithful to dry season home ranges across years (Loarie et al. 2009b); consequently, we assumed that during the wet season elephants were more likely to make exploratory forays

or use corridors. Using only locations recorded during the core wet season (December through March, inclusive), individuals with more than 100 locations during this period were retained for the analysis, resulting in 79 individuals (53 females, each representing a breeding herd, and 26 males). An additional nine elephants (6 females and 3 males) were collared in the Limpopo region (Figure 1) and used to test model fit.

The local convex hull ( $\mathrm{LOCOH}$ ) nonparametric kernel method was used to generate a home range for each individual (Getz and Wilmers 2004). The adaptive sphere of influence ( $a$ - 


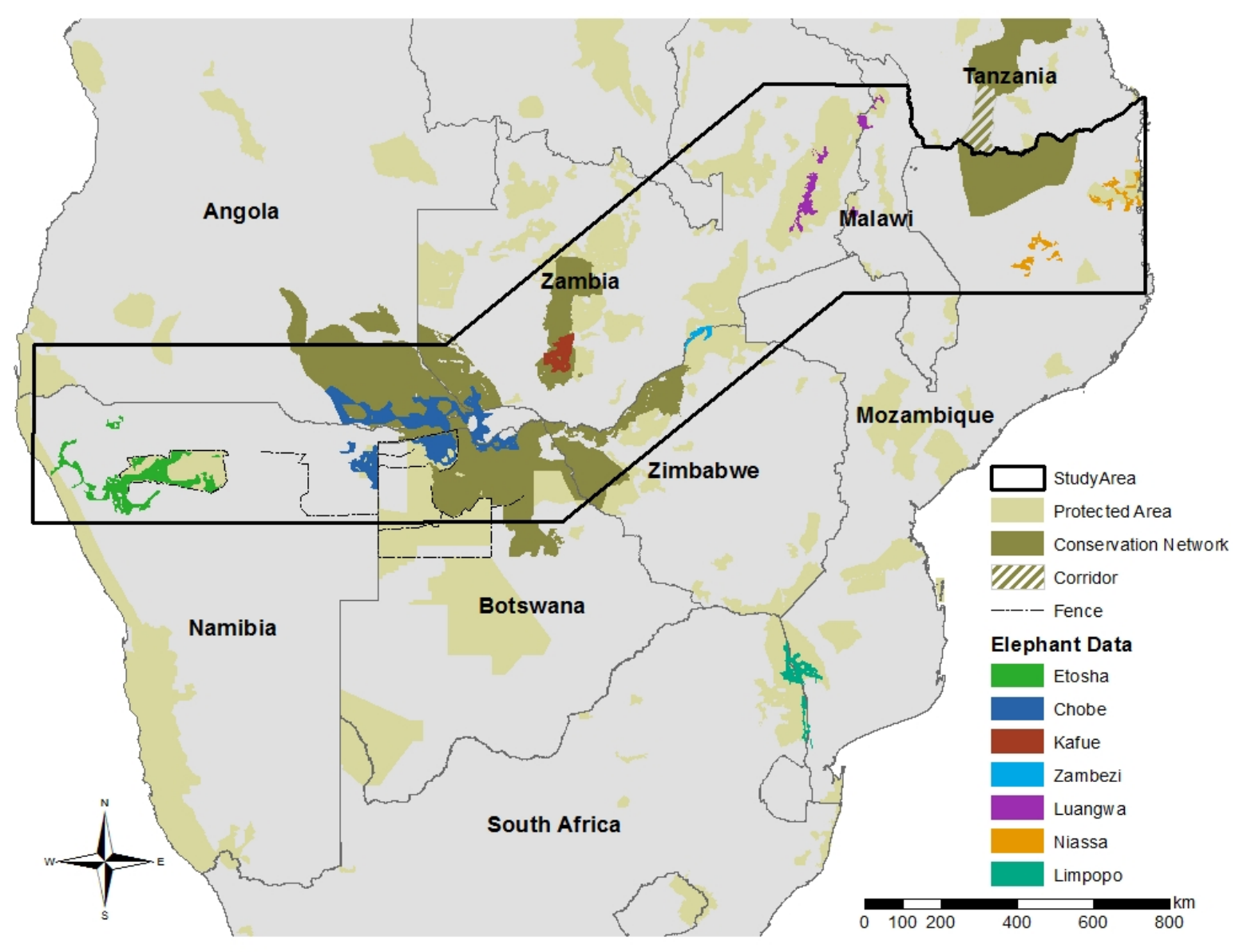

Figure 1. Map of the study area in southern Africa incorporating seven countries. Areas with elephant telemetry data were grouped into clusters based on location and following the designation proposed by van Aarde and Ferreira (2009). Data from the Limpopo cluster were used for out-of-sample model testing.

LoCoH) algorithm was used to construct kernels, with $a$ equal to the furthest distance between any two locations (Getz et al. 2007). The resulting home ranges fit tightly to the animal locations, often leaving holes which we believed were unrealistic; therefore, we further buffered home ranges by $10 \mathrm{~km}$. This had the added advantage of further identifying areas which elephants presumably had access to but did not use. Home ranges were created using $\mathrm{R}$ 
software (R Development Core Team 2011), along with the packages "adehabitat" (Calenge 2006) and "NNCH" (Wayne Getz Lab 2005).

\subsection{Habitat Covariates}

Habitat covariates known to influence elephant habitat selection and home range placement were used in the analysis. These included surface water (de Beer et al. 2006; Harris et al. 2008), slope (Wall et al. 2006), vegetation cover (Harris et al. 2008; Loarie et al. 2009a), and human presence (Harris et al. 2008; Hoare and Du Toit 1999; Jackson et al. 2008). Wet season surface water was located using data from Tracks4Africa (2010) and man-made watering point data provided by conservation authorities. These data were manually validated against Landsat imagery and missing water bodies were hand-digitized. Distance to water $(\mathrm{km})$ was then calculated for each location. It should be noted that small water bodies, such as mud holes, could not be identified with this method. Using a $90 \mathrm{~m}^{2}$ digital elevation model, slope was derived in degrees (Jarvis et al. 2006). Vegetative structure was characterized using MODIS Vegetation Continuous Fields (Hansen et al. 2006), which estimates the proportion of tree and herbaceous cover at a $500 \mathrm{~m}^{2}$ resolution. Owing to collinearity between tree and herbaceous cover within clusters, only proportion of tree cover was included in the analysis. Finally, human presence was represented using two variables. Landscan (2008) human population data estimated daily human density at a resolution of $1 \mathrm{~km}^{2}$, and road infrastructure data (Tracks4Africa 2010) was used to determine distance $(\mathrm{km})$ of locations from main and secondary roads. Distance to main roads was calculated using roads categorized as freeway, national road, or main road. All other road categories were included in the secondary road 
classification. All geospatial analysis was completed using the Spatial Analyst extension of ArcGIS 10.0 (ESRI 2010) and Geospatial Modelling Environment (Beyer 2011).

\subsection{Habitat Selection Models}

Habitat selection was modelled separately for males and females and combined across the six clusters. Elephant locations (1) were compared to randomly generated locations (0) using a mixed-effects logistic regression model. The random intercept was used to control for the lack of independence of points within individuals and unbalanced sample sizes (Gillies et al. 2006). We used a design III RSF approach (Manly et al. 2002), where random locations were generated within the $10 \mathrm{~km}$ buffered home range of each elephant at a density of 3 points $/ \mathrm{km}^{2}$. Since the scale of the largest habitat covariate was $1 \mathrm{~km}^{2}$, we were aware that contamination could be an issue (Keating and Cherry 2004). Contamination occurs when the use and random locations occur within the same pixel. Therefore, the density of random points was chosen to reduce contamination to less than $20 \%$ based on Johnson et al. (2006).

All habitat variables were used to assess elephant habitat selection, as they are all known to influence elephant habitat selection (Roever et al. 2012). No variables were highly correlated when examined using Pearson's correlation coefficient $(r>0.6)$. Each continuous variable was tested for the presence of a nonlinear relationship using a quadratic term. Model fit was evaluated using $k$-fold cross validation $(k=5)$ and the Spearman rank correlation coefficient (Boyce et al. 2002). Model fit was further evaluated using the independent elephant data from Limpopo following a similar method to k-fold cross validation, whereby the predicted RSF scores are placed in equal-area bins. The number of elephant locations falling into each bin 
is then tallied. Bins of higher RSF scores are expected to have higher frequencies of observations, and significance is tested using the Spearman rank correlation coefficient (Boyce et al. 2002).

Using the RSF model results, we created a habitat use index for males and females. We applied this model to the entire study area. To maintain predictive integrity, model predictions were limited to habitats observed in the model. For instance, the maximum distance to water observed in the use and available data was $58 \mathrm{~km}$, consequently, any area further than $58 \mathrm{~km}$ from water was not assessed. Analyses were done using R software (R Development Core Team 2011) and the Ime4 package (Bates and Maechler 2010).

\subsection{Connectivity Models}

Connectivity between clusters was evaluated using circuit theory (McRae et al. 2008) and the program Circuitscape (McRae and Shah 2009). Home ranges were used as the source and end nodes of the circuit. Home ranges were combined into a single node if they were within $20 \mathrm{~km}$ of each other, unless they were separated by a fence. We used the one-to-many criterion, whereby one source was connected to all end nodes in an iterative fashion. The habitat use index created from the RSF model was used as the resistance surface. Areas with a high probability of use were assumed to allow a greater current flow (or less resistance) than those with a low probability of use. Owing to the processing limitations of the Circuitscape program, the study area was segmented into five sections and the habitat use index was generalized to $500 \mathrm{~m}^{2}$ pixels. We began by using only the habitat use index as the resistance surface, but then further limited movement by adding absolute barriers. Based on known elephant habitat use, 
we hypothesized that distance to water, slope, and human population density had maximum values which posed a complete barrier to movement. We defined absolute barriers as any value greater than values observed in 99 percent of the elephant telemetry locations of these covariates. Consequently, areas further than $48 \mathrm{~km}$ from water, with a slope greater than 11.4 degrees, or containing more than 45 people $/ \mathrm{km}^{2}$ were classified as absolute barriers.

\section{Results}

\subsection{Habitat selection}

Both male and female wet season habitat selection models provided good fit using k-fold cross validation (Spearman rank $r_{s}=0.782, p=0.01$ for females and $r_{s}=0.952, p<0.01$ for males). Relative to availability, female elephants selected areas with low slopes, high tree cover, and low human population density (Table 2, Figure 2). They preferred to be further from main

Table 2. Coefficient estimates and standard errors for habitat selection models. Significance to $p=0.001$ is indicated $(* * *)$, and quadratic terms not included in the final model are denoted (-).

\begin{tabular}{|c|c|c|c|c|c|c|}
\hline & \multicolumn{3}{|c|}{ Females } & \multicolumn{3}{|c|}{ Males } \\
\hline & Estimate & SE & & Estimate & SE & \\
\hline Distance to water & -0.227 & 0.025 & $* * *$ & -0.426 & 0.033 & $* * *$ \\
\hline 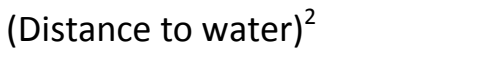 & 0.055 & 0.006 & $* * *$ & 0.128 & 0.008 & $* * *$ \\
\hline Slope & -0.175 & 0.010 & $* * *$ & -0.085 & 0.004 & $* * *$ \\
\hline$(\text { Slope })^{2}$ & 0.002 & 0.001 & $* * *$ & - & - & \\
\hline Proportion tree cover & 0.541 & 0.097 & $* * *$ & 7.452 & 0.418 & $* * *$ \\
\hline (Proportion tree cover) $^{2}$ & - & - & & -8.126 & 0.762 & $* * *$ \\
\hline Human population density & -0.010 & 0.001 & $* * *$ & -0.002 & 0.001 & $* * *$ \\
\hline Distance to main road & 0.092 & 0.006 & $* * *$ & 0.074 & 0.008 & $* * *$ \\
\hline Distance to secondary road & -0.073 & 0.022 & $* * *$ & -0.530 & 0.028 & $* * *$ \\
\hline 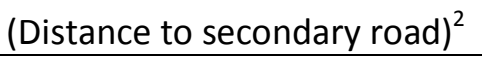 & 0.018 & 0.004 & $* * *$ & 0.025 & 0.005 & $* * *$ \\
\hline
\end{tabular}




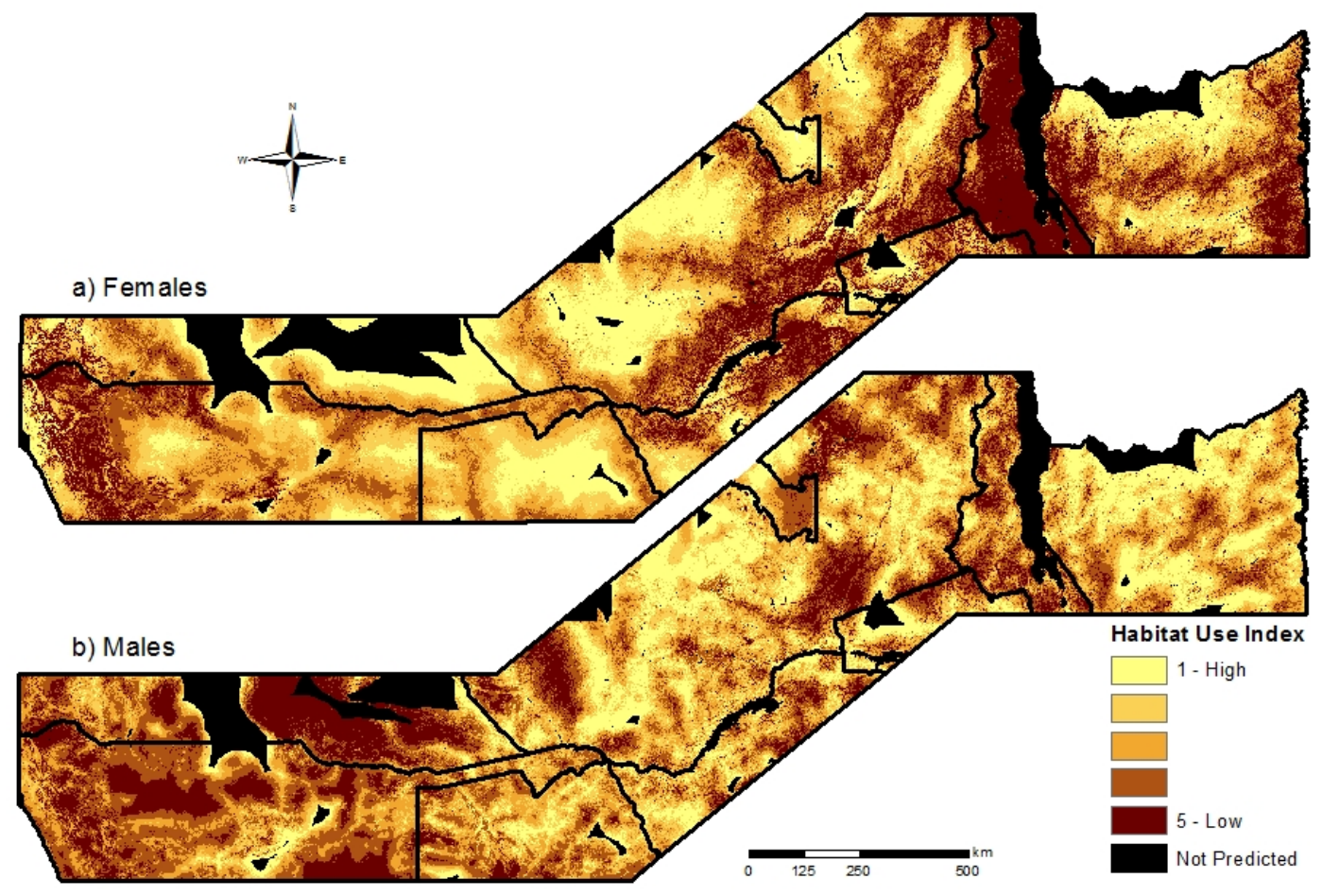

Figure 2. Relative index of habitat use for female (a) and male (b) elephants. Black regions represent areas that were not predicted because the variable values were outside of the range observed within the habitat selection model.

roads and had a nonlinear relationship with secondary roads, showing slight selection for areas near these roads but mostly avoiding them. Selection for water also had a nonlinear relationship, with females selecting areas both near and far from water relative to availability. Male elephants selected low slopes and low human population density, and they preferred areas of intermediate tree cover. Males avoided main roads but selected secondary roads. A nonlinear relationship with water also was present for males; however, they were less inclined 
to be close to water as compared with females. Model validation using the independent Limpopo data was significant for males $\left(r_{s}=0.6364, p=0.05\right)$ but not for females $\left(r_{s}=-0.6969, p\right.$ $=0.03$, indicating the female model was a poor predictor of elephant use in regions beyond the study area.

\subsection{Connectivity}

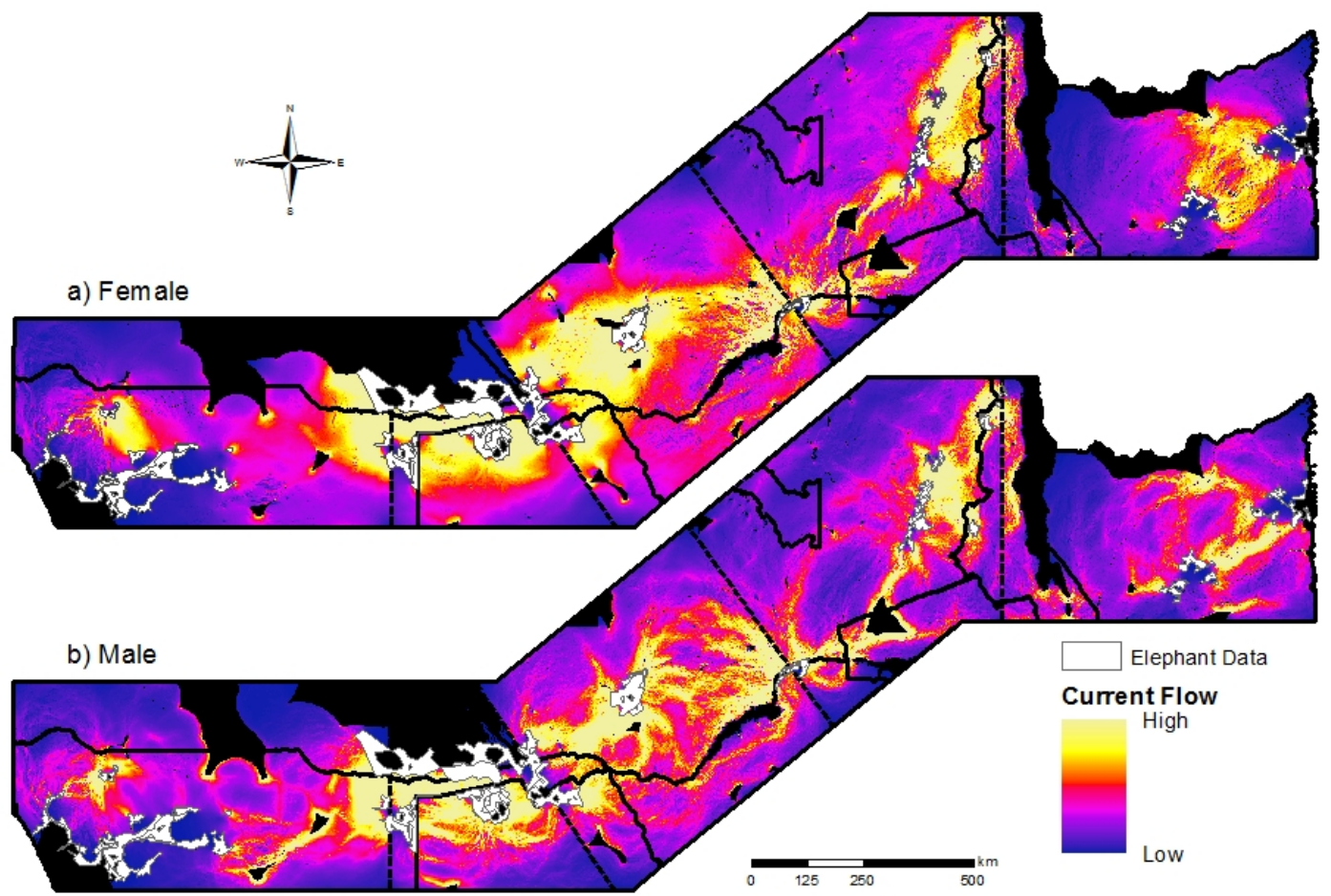

Figure 3. Current flow using the habitat selection index as the resistance. Owing to the computing limitations of the program Circuitscape, the study area was divided into five sections (dashed black line). Black regions indicate areas of zero flow. 
Adding absolute barriers to the circuit theory current flow maps did not alter connectivity between clusters, however barriers did restrict the width and alter the location of potential corridors. For both maps, current flow was high between Chobe and Kafue for male and female elephants (Figure $3 \& 4$ ). The high flow can be attributed to wide areas of suitable habitat allowing for multiple routes of travel. Potential corridors between the Zambezi cluster and its neighbouring clusters, Kafue and Luangwa, were less straightforward. When examining the current flow map without absolute barriers, it appeared that a corridor could exist between the Zambezi and Kafue clusters (Figure 3). However, the steep terrain between the two clusters added several absolute barriers, narrowing the corridor and shifting flow to the southwest (Figure 4). In the easterly direction, the connection between the Zambezi and Luangwa had some support in both current flow maps (Figure $3 \& 4)$. This corridor was long $(320 \mathrm{~km})$ and narrow, which could limit its utility. Flow also decreased for females in some areas between the Zambezi and Luangwa, further reducing its functionality as a potential corridor.

The current flow maps further showed low flow for males or females between Etosha and Chobe and between Luangwa and Niassa (Figure $3 \& 4$ ). The distance between Etosha and Chobe was large $(300 \mathrm{~km})$ and the area contained few water sources. In the Namibian portion of our study area, some regions were up to $70 \mathrm{~km}$ from water, and in Angola, this distance rose to greater than $100 \mathrm{~km}$. The furthest any elephant occurred from water was $58 \mathrm{~km}$, with a mean distance of $10 \mathrm{~km}$. The greatest barrier for dispersal between Luangwa and Niassa was the high human density in Malawi. In addition, Lake Malawi created a bottleneck, limiting potential flow to one $11 \mathrm{~km}$ wide area. 


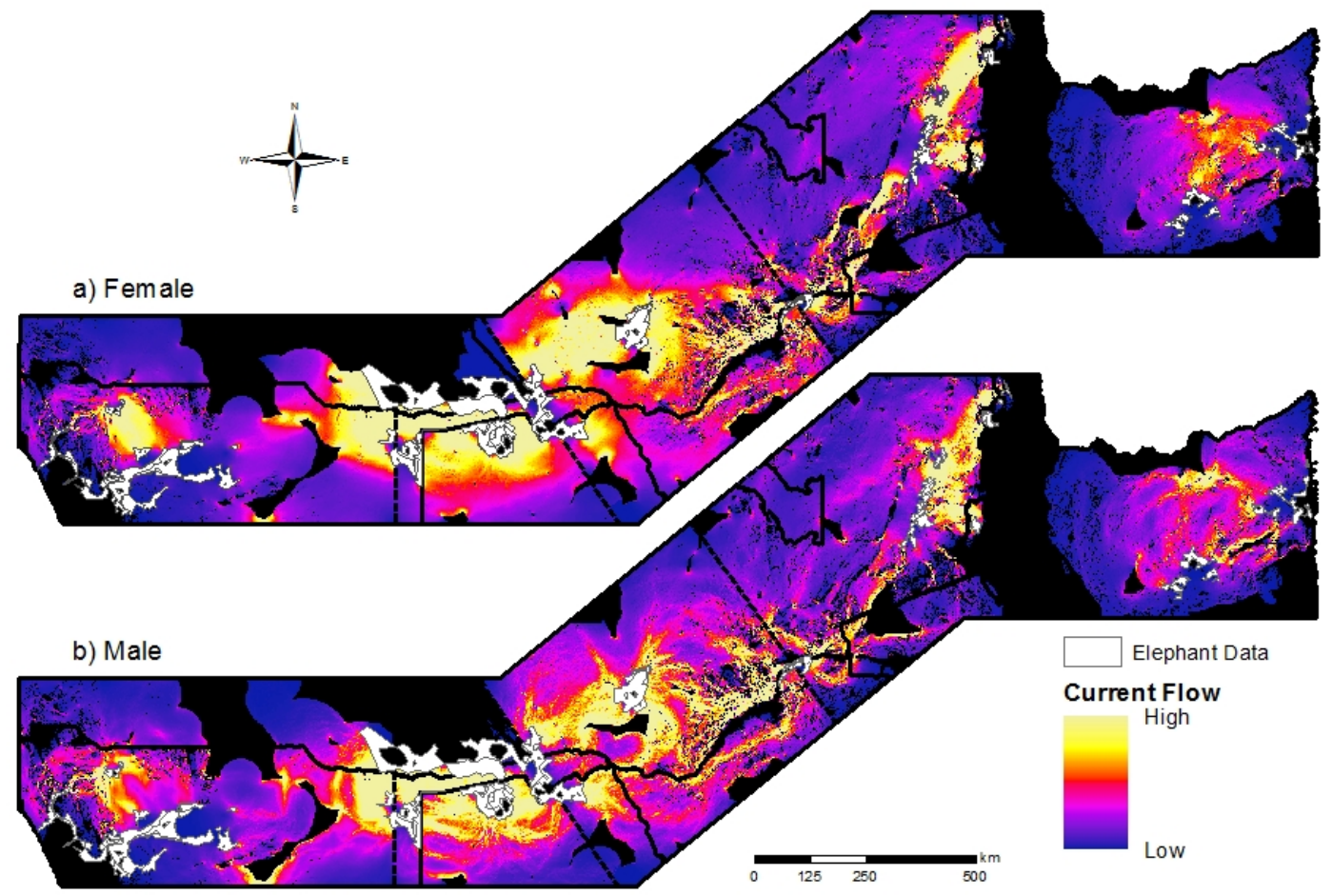

Figure 4. Current flow using the habitat selection index as the resistance, along with absolute barriers. Absolute barriers were defined as values greater than those observed within 99 percent of the elephant location data for distance to water, human population density, and slope. Black regions indicate areas of zero flow.

\section{Discussion}

In general, the wet season habitat selection patterns of male and female elephants were similar and supported the relevance of previously reported habitat covariates (see Harris et al. 2008; Hoare and Du Toit 1999; Loarie et al. 2009a; Roever et al. 2012; Wall et al. 2006). Both sexes had a nonlinear relationship with water, selecting for areas both near and far from water 
relative to availability (Table 2). This agrees with what we know about elephant behaviour, as elephants regularly go to water to drink and then travel far afield in search of food (Leggett 2006). Our elephants also avoided steep terrain, possibly due to due to physiological and energetic constraints (see Wall et al. 2006). Females had a sharper decline in the use of higher slopes with the inclusion of the quadratic term, suggesting that they selected more for flat terrain than males. Both sexes also avoided areas of high human density as well as areas near main roads. Males, however, remained closer to secondary roads, while females avoided them.

Our circuit theory current maps identified potential corridors among several clusters of protected areas in the central portion of the study area (Figures $3 \& 4$ ). Between the Chobe and Kafue clusters, we identified a wide area suitable for potential animal movement, supporting the functionality of the Kavango-Zambezi TFCA. Our maps further indicate that the Zambezi cluster may be connected to the Kavango-Zambezi TFCA via Kafue and an additional corridor through Zimbabwe. The Zambezi cluster was only $67 \mathrm{~km}$ from the Zimbabwe portion of the Kavango-Zambezi TFCA, and although we had no data from elephant populations in Zimbabwe, a potential corridor to the TFCA was identified by both female and male current flow maps. In addition to highlighting connectivity around the Kavango-Zambezi TFCA, the current flow maps also identified a potential corridor between the Zambezi and Luangwa cluster. The steep terrain of the Muchinga Mountains, north of the Zambezi cluster, restricted potential animal movements between Luangwa and Zambezi; however, this mountain range also restricted human development. Elephants are capable of living in such habitats, as seen with elephants in the Etosha cluster which occur within the Etendeka Mountains; therefore, the viability of this corridor should not be discounted. It is estimated that 58 percent of African 
elephants occur within southern Africa, and of those approximately 85 percent are located in the Chobe, Kafue, Luangwa and Zambezi clusters (see Blanc et al. 2007). Consequently, the provision of these corridors linking Chobe, Kafue, Luangwa, and Zambezi will unite most of southern Africa's elephants into a single entity that could function as a metapopulation.

The main factors limiting connectivity across the study area where access to surface water in the west and a high human density in the east. Elephants in the Etosha cluster are effectively isolated by the lack of water in areas east of the cluster. Blanc et al. (2007) suggested that elephants' range possibly extended east of Etosha and north into Angola. While elephants have been recolonizing south eastern Angola after the civil war ended in 2002 (Chase and Griffin 2011), our results indicate that it is unlikely that elephants will cross the arid regions of northcentral Namibia and south-central Angola. In the east, the potential corridor between Luangwa and Niassa was not limited by water, but instead, the high human density present in Malawi. Hoare and du Toit (1999) found the elephants in Zimbabwe did not coexist with humans when the latter reached a density of 15.6 persons $/ \mathrm{km}^{2}$. Within our data, only 4.8 percent of elephant telemetry locations $(1,919$ of 39,900) exceeded Hoare and du Toit's threshold. Elephants occurred in areas with a maximum human density of 1,512 persons $/ \mathrm{km}^{2}$, showing that elephants can and do penetrate areas of higher human density. Whether they could exist in

these areas for very long, though, is questionable, particularly without a nearby refuge. Unfortunately, Malawi has few areas outside of parks and game reserves with human densities below 15.6 persons $/ \mathrm{km}^{2}$, so the potential for connectivity between Luangwa and Niassa is 
unlikely. Our results therefore suggest that the Etosha and Niassa clusters have limited potential to be managed as a spatially structured metapopulation within the conservation areas examined in this study and, importantly, connectivity along an east-west axis may be limited.

Despite the lack of connectivity between Niassa and the other clusters examined in this study, the Niassa cluster still might benefit from inclusion with other conservation areas in northern Mozambique and southern Tanzania. Current flow maps showed connectivity not only between elephant data within the Niassa Cluster but also a potential corridor to Niassa Game Reserve. The Niassa Game Reserve is connected by the Selous-Niassa Corridor to Selous Game Reserve in southern Tanzania (Hofer et al. 2004; Figure 1), and elephants in this region could benefit from being connected to and managed collectively with those in the Niassa and Selous Game Reserves (see Baldus et al. 2003).

Here, we used habitat selection models to identify corridors for elephants, making the assumption that habitat use reflects landscape resistance. However, other behavioural factors not identified in the model may also influence dispersal (Belisle 2005; Lima and Zollner 1996). One limitation we observed was the inability to incorporate the periodic nature of elephants moving near and far from water. The region highlighted as a potential corridor for males between the Zambezi and Luangwa had a $240 \mathrm{~km}$ expanse without crossing water. It is unrealistic to assume that this route would be a viable corridor for elephants; however it should not be completely discounted. The female current flow maps for the same region identified portions of the Luangwa River, located $45 \mathrm{~km}$ to the northwest, as a viable corridor. 
Consequently, incorporating the width of the valley into the corridor design may make this potential route more viable for both sexes.

Using RSF models to make predictions about elephant use in areas other than the study area can be problematic (Boyce et al. 2002), as seen in our independent testing data from Limpopo. The female model had poor fit; consequently, models should be used with caution and corridors should be further validated with field data. In our analysis, we attempted to limit unrealistic predictions by bounding all variables to values only seen within the model; however, this does not compensate for changes in the proportion of each variable (Aarts et al. 2008; Matthiopoulos et al. 2011). For the current flow maps, we suspect that adding absolute barriers using the $99^{\text {th }}$ percentile of elephant locations produced more realistic predictions. While elephants used extreme areas of slope, human density, and distance to water, these forays were rare and the animal did not generally penetrate far into these less hospitable habitats. Therefore, it is plausible to assume that corridors based on these extreme values will have limited utility; however, this deduction also requires further validation.

Speculation has it that elephants were once wide-spread across Africa, but current populations have become fragmented and compressed into isolated protected areas (see Blanc et al. 2007). Interrupting natural movement patterns in elephants intensifies the damage that these ecosystem engineers cause to vegetation (Loarie et al. 2009b; van Aarde et al. 2006). Increasing connectivity between elephant populations is expected to alleviate problems caused by confinement and induce a dynamic that stabilizes populations regionally and removes the concern of local "hyper-abundance" (van Aarde and Jackson 2007). Based on the results of this 
study, elephant dispersal along the east-west gradient is plausible across much of our study area; therefore, if corridors are projected and enhanced, the foundations for a metapopulation as suggested in van Aarde and Jackson (2007) could be implemented. However, connectivity alone does not constitute a metapopulation (Driscoll 2007), and the presence of a corridor does not guarantee dispersal. The functionality of corridors must be monitored and, where necessary, promoted to ensure the continued flow between populations. Without active management efforts to maintain connectivity between protected areas along the east-west axis, it is likely that human development and encroachment will continue to isolate wildlife in southern Africa.

This study represents the largest effort to identity connectivity for a species to which we are aware, crossing seven countries. Yet these techniques are universally applicable at a variety of spatial scales and provide quantitative measures of habitat selection and animal flow rates (McRae et al. 2008). They require limited data input, they rely on realized habitat use by the animal, and they need little inferences by the authors or other sources of expert opinion (Chetkiewicz and Boyce 2009). Ultimately, habitat fragmentation is a global problem, and conservation and management efforts need tools to quickly identify and focus research efforts in areas where we have the highest probability to successfully restore connectivity.

\section{Acknowledgements}

We would like to thank the Conservation Foundation Zambia, Conservation International's southern Africa's Wildlife Programme, Conservation Lower Zambezi, the International Fund for Animal Welfare, the Mozal Community Development Trust, the National Research Foundation, 
the National Postcode Lottery of the Netherlands, the Peace Parks Foundation, the US Fish and Wildlife Services, the University of Pretoria, the World Wildlife Fund (SARPO; Mozambique; SA), the Walt Disney Grant Foundation, and the Wildlifewins Lottery for several years of research funding to RJ van Aarde. GIS and logistical support was provided by Bateleurs, South African National Parks, Tracks4Africa, and Wings for Wildlife. This research was sanctioned and supported by the Botswana Department of Wildlife \& National Parks, Direcção Nacional de Areas de Conservação, the Namibian Ministry of Tourism \& Environment, the Malawian Wildlife Department, South African National Parks, and the Zambian Wildlife Authority. 


\section{References}

Aarts, G., MacKenzie, M., McConnell, B., Fedak, M., Matthiopoulos, J., 2008. Estimating spaceuse and habitat preference from wildlife telemetry data. Ecography 31, 140-160.

Baldus, R.D., Hahn, R., Mpanduji, D.G., Siege, L., 2003. The Selous-Niassa Wildlife Corridor, In Tanzania Wildlife Discussion Paper No. 34. eds R.D. Baldus, L. Siege. Deutsche Gesellschaft für Technische Zusammenarbeit, Dar Es Salaam.

Bartlam-Brooks, H.L.A., Bonyongo, M.C., Harris, S., 2011. Will reconnecting ecosystems allow long-distance mammal migrations to resume? A case study of a zebra Equus burchelli migration in Botswana. Oryx 45, 210-216.

Bates, D., Maechler, M., 2010. Linear mixed-effects models using S4 classes. R package version 0.999375-37.

Beier, P., Noss, R.F., 1998. Do habitat corridors provide connectivity? Conservation Biology 12 , 1241-1252.

Belisle, M., 2005. Measuring landscape connectivity: The challenge of behavioral landscape ecology. Ecology 86, 1988-1995.

Berger, J., 2004. The last mile: How to sustain long-distance migration in mammals. Conservation Biology 18, 320-331.

Beyer, H.L., 2011. Geospatial Modelling Environment. Spatial Ecology, LLC.

Blanc, J.J., Barnes, R.F.W., Craig, G.C., Dublin, H.T., Thouless, C.R., Douglas-Hamilton, I., Hart, J.A., 2007. African elephant status report 2007: An update from the African elephant database. Occasional Paper Series of the IUCN Species Survival Commission, No. 33. IUCN/SSC African Elephant Specialist Group. IUCN, Gland, Switzerland. 
Boyce, M.S., Vernier, P.R., Nielsen, S.E., Schmiegelow, F.K.A., 2002. Evaluating resource selection functions. Ecological Modelling 157, 281-300.

Brown, D.E., Conover, M.R., 2011. Effects of Large-Scale Removal of Coyotes on Pronghorn and Mule Deer Productivity and Abundance. Journal of Wildlife Management 75, 876-882.

Calenge, C., 2006. The package "adehabitat" for the R software: A tool for the analysis of space and habitat use by animals. Ecological Modelling 197, 516-519.

Chase, M.J., Griffin, C.R., 2011. Elephants of south-east Angola in war and peace: their decline, re-colonization and recent status. African Journal of Ecology 49, 353-361.

Chetkiewicz, C.-L.B., Clair, C.C.S., Boyce, M.S., 2006. Corridors for conservation: Integrating pattern and process. Annual Review of Ecology Evolution and Systematics 37, 317-342.

Chetkiewicz, C.L.B., Boyce, M.S., 2009. Use of resource selection functions to identify conservation corridors. Journal of Applied Ecology 46, 1036-1047.

Conover, M.R., Kania, G.S., 1995. Annual variation in white-tailed deer damage in commercial nurseries. Agriculture Ecosystems \& Environment 55, 213-217.

Corner, L.A.L., 2006. The role of wild animal populations in the epidemiology of tuberculosis in domestic animals: How to assess the risk. Veterinary Microbiology 112, 303-312.

Coughenour, M.B., 2008. Causes and consequences of herbivore movement in landscape ecosystems In Fragmentation in Semi-Arid and Arid Landscapes, Consequences for Human and Natural Systems. eds K.A. Galvin, R.S. Reid, R.H.J. Behnke, N.T. Hobbs, pp. 45-91. Springer, Dordrecht. 
Couvreur, M., Christiaen, B., Verheyen, K., Hermy, M., 2004. Large herbivores as mobile links between isolated nature reserves through adhesive seed dispersal. Applied Vegetation Science 7, 229-236.

Crooks, K.R., 2002. Relative sensitivities of mammalian carnivores to habitat fragmentation. Conservation Biology 16, 488-502.

Crooks, K.R., Sanjayan, M. eds., 2006. Connectivity Conservation. Cambridge University Press, Cambridge.

Cushman, S.A., Chase, M., Griffin, C., 2010. Mapping landscape resistance to identify corridors and barriers for elephant movement in southern Africa. Springer, Tokyo.

de Beer, Y., Kilian, W., Versfeld, W., van Aarde, R.J., 2006. Elephants and low rainfall alter woody vegetation in Etosha National Park, Namibia. Journal of Arid Environments 64, 412-421.

Driscoll, D.A., 2007. How to find a metapopulation. Canadian Journal of Zoology-Revue Canadienne De Zoologie 85, 1031-1048.

Dublin, H.T., Sinclair, A.R.E., McGlade, J., 1990. Elephants and fire as causes of multiple stabel states in the Serengeti-Mara woodlands. Journal of Animal Ecology 59, 1147-1164.

Epps, C.W., Wehausen, J.D., Bleich, V.C., Torres, S.G., Brashares, J.S., 2007. Optimizing dispersal and corridor models using landscape genetics. Journal of Applied Ecology 44, 714-724.

ESRI, 2010. ArcGIS version 10.0. Environmental Systems Research Institute (ESRI), Redlands.

Getz, W.M., Fortmann-Roe, S., Cross, P.C., Lyons, A.J., Ryan, S.J., Wilmers, C.C., 2007. LoCoH: Nonparameteric Kernel Methods for Constructing Home Ranges and Utilization Distributions. PLoS ONE 2, e207. 
Getz, W.M., Wilmers, C.C., 2004. A local nearest-neighbor convex-hull construction of home ranges and utilization distributions. Ecography 27, 489-505.

Gillies, C.S., Hebblewhite, M., Nielsen, S.E., Krawchuk, M.A., Aldridge, C.L., Frair, J.L., Saher, D.J., Stevens, C.E., Jerde, C.L., 2006. Application of random effects to the study of resource selection by animals. Journal of Animal Ecology 75, 887-898.

Hanks, J., 2001. Conservation strategies for Africa's large mammals. Reproductive Fertility and Development 13, 459-468.

Hansen, M., DeFries, R.S., Townshend, J.R., Carroll, M., Dimiceli, C., Sohlberg, R., 2006. Vegetation Continuous Fields MOD44B, 2001 Percent Tree Cover, Collection 4. University of Maryland, College Park, Maryland, 2001.

Harris, G.M., Russell, G.J., van Aarde, R.I., Pimm, S.L., 2008. Rules of habitat use by elephants Loxodonta africana in southern Africa: insights for regional management. Oryx 42, 6675.

Herfindal, I., Linnell, J.D.C., Moa, P.F., Odden, J., Austmo, L.B., Andersen, R., 2005. Does Recreational Hunting of Lynx Reduce Depredation Losses of Domestic Sheep? The Journal of Wildlife Management 69, 1034-1042.

Hoare, R.E., Du Toit, J.T., 1999. Coexistence between people and elephants in African savannas. Conservation Biology 13, 633-639.

Hobbs, N.T., 1996. Modification of Ecosystems by Ungulates. The Journal of Wildlife Management 60, 695-713.

Hofer, H., Hildebrandt, T.B., Goritz, F., East, M.L., Mpanduji, D.G., Hahn, R., Siege, L., Baldus, R.D., 2004. Distribution and movement of elephants and other wildlife in the Selous- 
Niassa Wildlife Corridor, Tanzania, In Tropical Ecology Support Programme. ed. G. Hoebart, Eschborn.

Jackson, T.R., Mosojane, S., Ferreira, S.M., van Aarde, R.J., 2008. Solutions for elephant Loxodonta africana crop raiding in northern Botswana: moving away from symptomatic approaches. Oryx 42, 83-91.

Janzen, D.H., 1984. Dispersal of small seeds by big herbivores - Foliage is the fruit. American Naturalist 123, 338-353.

Jarvis, A., Reuter, H.I., Nelson, A., Guevara, E., 2006. Hole-filled seamless SRTM data V3. International Centre for Tropical Agriculture (CIAT).

Johnson, C.J., Nielsen, S.E., Merrill, E.H., McDonald, T.L., Boyce, M.S., 2006. Resource selection functions based on use-availability data: Theoretical motivation and evaluation methods. Journal of Wildlife Management 70, 347-357.

Keating, K.A., Cherry, S., 2004. Use and interpretation of logistic regression in habitat selection studies. Journal of Wildlife Management 68, 774-789.

LandScan, 2008. High Resolution global Population Data Set. Copyrighted by UT-Battelle, LLC, operator of Oak Ridge National Laboratory under Contract No. DE-AC05-00OR22725 with the United States Department of Energy.

Leggett, K., 2006. Effect of artificial water points on the movement and behaviour of desertdwelling elephants of north-western Namibia. Pachyderm 40, 40-51.

Lima, S.L., Zollner, P.A., 1996. Towards a behavioral ecology of ecological landscapes. Trends in Ecology \& Evolution 11, 131-135. 
Loarie, S.R., van Aarde, R.J., Pimm, S.L., 2009a. Elephant seasonal vegetation preferences across dry and wet savannas. Biological Conservation 142, 3099-3107.

Loarie, S.R., Van Aarde, R.J., Pimm, S.L., 2009b. Fences and artificial water affect African savannah elephant movement patterns. Biological Conservation 142, 3086-3098.

Madhusudan, M.D., 2003. Living amidst large wildlife: Livestock and crop depredation by large mammals in the interior villages of Bhadra Tiger Reserve, south India. Environmental Management 31, 466-475.

Manier, D.J., Hobbs, N.T., 2006. Large herbivores influence the composition and diversity of shrub-steppe communities in the Rocky Mountains, USA. Oecologia 146, 641-651.

Manly, B.F.J., McDonald, L.L., Thomas, D.L., McDonald, T.L., Erickson, W.P., 2002. Resource Selection by Animals: Statistical Design and Analysis for Field Studies, 2nd edn. Kluwer Academic Publishers, Dordrecht.

Matthiopoulos, J., Hebblewhite, M., Aarts, G., Fieberg, J., 2011. Generalized functional responses for species distributions. Ecology 92, 583-589.

McRae, B.H., Dickson, B.G., Keitt, T.H., Shah, V.B., 2008. Using circuit theory to model connectivity in ecology, evolution, and conservation. Ecology 89, 2712-2724.

McRae, B.H., Shah, V.B., 2009. Circuitscape Version 3.5.4. The University of California, Santa Barbara.

Mittermeier, R.A., Mittermeier, C.G., Brooks, T.M., Pilgrim, J.D., Konstant, W.R., da Fonseca, G.A.B., Kormos, C., 2003. Wilderness and biodiversity conservation. Proceedings of the National Academy of Sciences of the United States of America 100, 10309-10313. 
Morrison, J.C., Sechrest, W., Dinerstein, E., Wilcove, D.S., Lamoreux, J.F., 2007. Persistence of large mammal faunas as indicators of global human impacts. Journal of Mammalogy 88, 1363-1380.

Pringle, R.M., Young, T.P., Rubenstein, D.I., McCauley, D.J., 2007. Herbivore-initiated interaction cascades and their modulation by productivity in an African savanna. Proceedings of the National Academy of Sciences of the United States of America 104, 193-197.

Puth, L.M., Wilson, K.A., 2001. Boundaries and corridors as a continuum of ecological flow control: Lessons from rivers and streams. Conservation Biology 15, 21-30.

R Development Core Team, 2011. R: A language and environment for statistical computing. R Foundation for Statistical Computing, Vienna, Austria. ISBN 3-900051-07-0.

Roever, C.L., Van Aarde, R.J., Leggett, K., 2012. Functional responses in the habitat selection of a generalist mega-herbivore, the African savannah elephant. Ecography 35, 1-11.

Scholes, R.J., Mennell, K.G. eds., 2008. Elephant Management, A Scientific Assessment for South Africa. Wits University Press, Johannesburg.

Tracks4Africa, 2010. Tracks4Africa Enterprises (Pty) Ltd. Unit 8 Innovation Center, Electron Street, Techno Park, Stellenbosch, 7599, Western Cape, South Africa.

Van Aarde, R.J., Ferreira, S.M., 2009. Elephant populations and CITES trade resolutions. Environmental Conservation 36, 8-10.

van Aarde, R.J., Jackson, T.P., 2007. Megaparks for metapopulations: Addressing the causes of locally high elephant numbers in southern Africa. Biological Conservation 134, 289-297. van Aarde, R.J., Jackson, T.P., Ferreira, S.M., 2006. Conservation science and elephant management in southern Africa. South African Journal of Science 102, 385-388. 
Wall, J., Douglas-Hamilton, I., Vollrath, F., 2006. Elephants avoid costly mountaineering. Current Biology 16, 527-529.

Wayne Getz Lab, 2005. LoCoH: A k-NNCH Implementation.

Western, D., Maitumo, D., 2004. Woodland loss and restoration in a savanna park: a 20-year experiment. African Journal of Ecology 42, 111-121. 